\title{
Resilience And Aggression Of Adolescents, Early And Middle- Aged Adults: Analyzing Gender Differences
}

\author{
Sabahat Naseem \\ \& \\ Seema Munaf \\ Institute of Clinical Psychology \\ University of Karachi
}

\begin{abstract}
The present study aimed to analyze gender difference in resilience and aggression of three developmental stages (adolescence, early adulthood, and middle adulthood). For this, comparative research design was utilized. Through purposive sampling, 600 participants $\left(M_{\text {age }}=28.24\right.$ years, $\left.S D=12.12\right)$ with males and females equal in number; were selected from different regions of Karachi, Pakistan. Participants' demographic information was collected through Respondent Information Form. Resilience and aggression were measured using The Brief Resilience Scale and Short Form of the Buss-Perry Aggression Questionnaire, respectively. Data was analyzed through independent samples $t$-test using SPSS. Results indicated that overall, resilience was significantly higher in males. In adolescence and early adulthood, resilience was higher in males than females, however, in middle adulthood, insignificant gender difference was noted in resilience. Further, overall non-significant gender difference was found in aggression; nevertheless, physical aggression was significantly higher in males, whereas, anger was higher in females. Moreover, insignificant gender difference was also found in aggression concerning the three age groups. This study would help in understanding the role of gender in resilience and aggression in different developmental stages. Additionally, it would assist in developing gender and age specific programs for fostering resilience and managing aggression.
\end{abstract}

Keywords: Gender, Resilience, Aggression, Adolescence, Early Adulthood, Middle Adulthood.

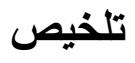

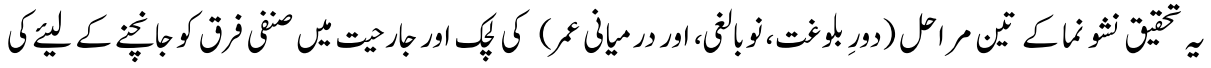

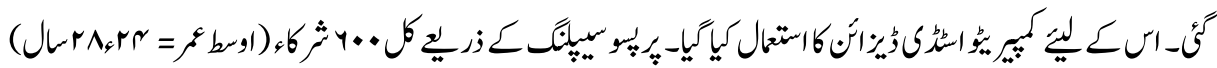

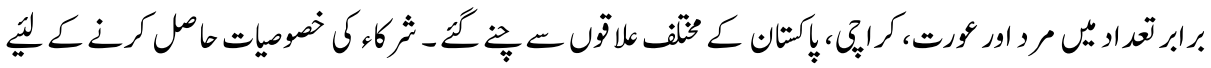

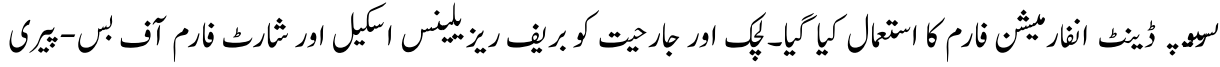

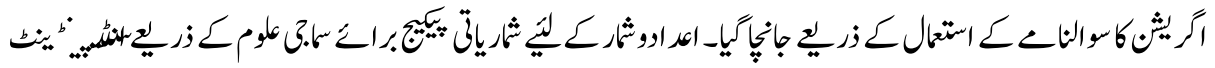




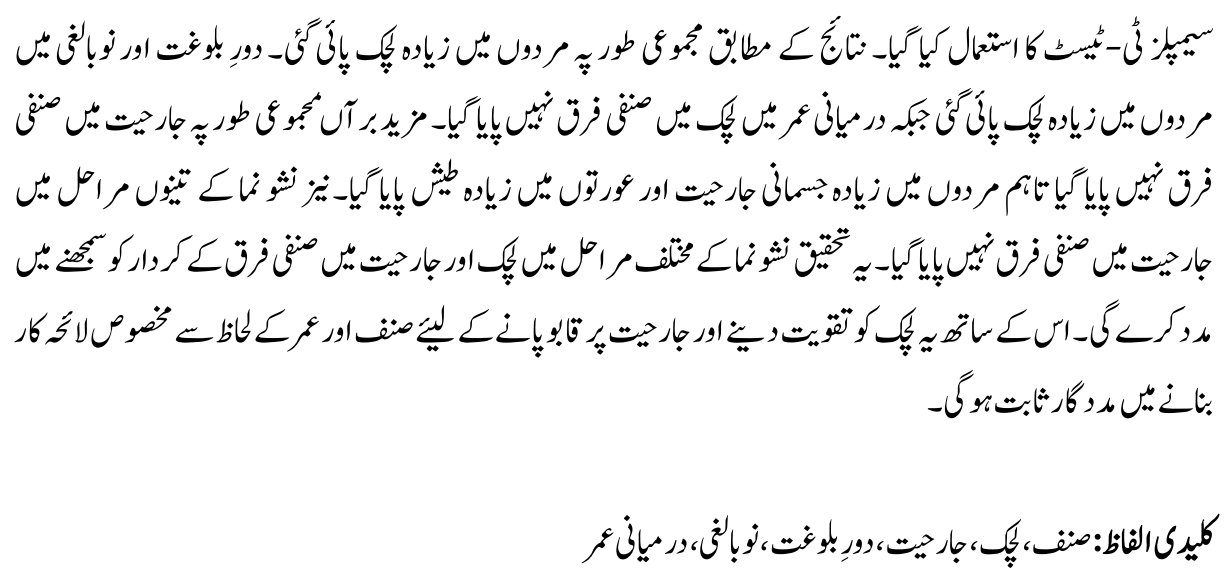

\section{Introduction}

Life is an expedition that includes a variety of positive and negative periods of time for every human being. The perception and definition of different circumstances may vary for people; nonetheless, everyone encounters numerous life stressors during some point in life. Adverse life events have a tendency to affect people's physical and psychological functioning. The manner in which an individual reacts during an adverse situation is largely contingent upon how one perceives that particular situation and on the personal and environmental resources as well (Parsons, et al., 2016). Some individuals are able to deal with the challenges in ways that assist them in avoiding or decreasing the odds of undesirable outcomes, whereas, others resort to unhealthy ways of dealing with the stressors which leads them towards negative consequences.

One of the chief characteristics that help people in keeping their emotions, cognitions, and behaviors under control during the times of distress is resilience. Resilience is described as an ability that helps people to refrain from resorting to maladaptive functioning upon encountering stressful times. It makes an individual capable of enduring the stress and difficult times without losing one's assets and bouncing back with better or the same level of stability and strength (Bezek, 2010). Resilience might not be present at one stage of life but may be developed later. Moreover, it can be modified with the help of various components all through one's lifetime. Resilience enables individuals to maintain their homeostasis and functioning despite of the stressors in their environment (Masten, 2011).

Another commonly observed manner in which individuals behave during times of distress and frustrations is aggression. The term aggression encompasses those behaviors that are intended to be harmful for another person who does not wish to be harmed. 
However, aggression is not always directed towards another person or an object, rather it may also be directed towards self (Bushman \& Huesmann, 2010). Different components of aggression have been identified and each of them serves a diverse function. These include physical aggression (physically inflicting harm such as through hitting, stabbing, punching, biting, etc.), relational aggression (impairing others' relationships), hostility (linked with the cognitive part of aggression such as having ill intentions, negative perceptions, etc.), verbal aggression (verbally inflicting harm such as by yelling, swearing, etc.), anger (negative affectivity), etc. (Rubio-Garay, et al., 2016).

Resilience enhances an individual's ability for adaptability and capacity to deal with the challenging circumstances in a constructive manner. Conversely, aggression leads to inadaptability and destructive ways of dealing with difficult situations. Keeping this notion in view, both of these variables have an inverse relationship. Resilience is a characteristic that assists in regulating emotions, enhances prosocial behavior, stimulates healthy coping mechanisms, and helps in maintaining healthy interpersonal relationships. All of this subsequently contributes to a low probability and/or decline in the manifestation of aggression (Kim et al., 2015). In addition to this, researches emphasize that due to its dynamic nature, individuals manifest resilience differently during different stages of development. Further, considering the development and modification of aggression over the period of life, researchers have noted that it is possible that the level of aggression may change over time. Moreover, if a child exhibits aggressive tendencies, there is a highly probably that he or she would display similar behavior during the later stages of development (adolescence and adulthood) as well (Kokko \& Pulkkinen, 2000).

Moreover, researches indicate that both males and females tend to utilize different avenues in their journey towards developing and manifesting resilience and aggression (Bezek, 2010). Gender differences that are observed in resilience and aggression tend to get influenced by a number of personal and environmental factors such as the role of biological and genetic makeup; personality traits; styles of coping; personal goals and aspirations; social, environmental and familial influences; communication skills; social support; etc. (Ahsan, 2015). In addition, the different roles that are assigned to both genders as defined by the societal and cultural values also add in to the way both males and females manifest resilience and aggression (Mwangi \& Ireri, 2017).

The manner in which gender impacts resilience and aggression is also stimulated by developmental stages. Among various determinants that influence the pathway of resilience and aggression during the lifecycle, the gender of an individual plays a highly substantial role. Each developmental phase brings along varying gender-specific roles, values, and interests. Therefore, alterations that are observed in an individual's resilience 
and aggression over the course of life tend to be different for males and females (Chaplin, 2015). Gender considerably effects the perceptions, emotions, and behaviors of an individual in a particular situation. As noted by, Blatt-Eisengart, et al., (2009), differences in an individual's perceptions and behaviors due to gender become evident during adolescence and continue through the later developmental stages.

Numerous researches indicate that males and females react differently in similar situations and demonstrate a variety of contrasting perceptions and behaviors. From childhood to adulthood, people come across multiple instances where they find the need to manifest resilience and/or aggression. It has been noted that, for both males and females, aggressive behavior in childhood is most likely to persist later in life and has the odds to impact not only the physical and mental health of the aggressive individual but also effects their personal and social life as well.

People of Pakistan have been struggling since long and encountering stressors regularly. In this country, equal access to opportunities and resources among both the genders is still a huge challenge as it ranks as third worst country on Gender Inequality Index (World Economic Forum, 2018). Moreover, researchers have frequently highlighted that the roles and experiences of males and females are greatly influenced by one's developmental stage, socio-cultural values, expectations, and practices. Many a times, due to the differences in their culturally-constrained gender roles, males and females tend to think, behave, and feel differently from one another even while experiencing similar situations.

Therefore, keeping these notions in mind, it is essential to thoroughly examine how gender differences contribute to the differences in people's level of resilience and aggression. In addition to this, it is also crucial to study the differences in resilience and aggression between males and females belonging to different developmental stages groups specifically in regards to Pakistani society.

\section{Review of Literature}

\section{Resilience and Aggression}

Resilience is not a static characteristic, rather its level and the way it processes keeps on changing with the changes in personal and environmental variables that are associated with it (Rutter, 2006). Literature suggests that individuals who are resilient demonstrate positive affectivity that assists them in utilizing healthy coping strategies and adapt well in different situations. Moreover, resilient individuals also tend to have higher psychological well-being and satisfaction with life (Carmona-Halty, et al., 2019). 
Considering the literature for aggression, Berkowitz (1993) noted that aggression can be a consequence of an instinct to defend oneself after some kind of provocation or it could also be used as a mechanism to achieve some goal. Moreover, the expression of aggression can be categorized into two types; direct aggression: when aggression is manifested in the presence of the person towards whom it is targeted and indirect aggression: when aggression is displayed in the absence of the victim (Archer \& Coyne, 2005). An ample amount of literature indicates that it is often the interaction of both innate/internal and external stimuli that determines the manifestation of aggressive behavior (Nisa \& Parveen, 2019).

The inverse relationship that exists between resilience and aggression has been studied widely in different populations and age groups. Among the various identified factors that play a protective role for resilience and, as a consequence, become a risk factor for aggression are prosocial skills, functioning of familial relationships, hormonal imbalances, intensity and severity of environmental stressors, etc. (Masten, 2011; Jaffee, et al., 2007). In addition, literature also indicates that people from different age groups who manifest resilience have been found to express lesser destructive behaviors and emotions including anger, aggression, and hostility (Akbari, 2017).

\section{Gender Difference in Resilience and Aggression}

Gender and its associated constructs (cognitions, behaviors, emotions, values, attitudes, etc.) impact all facets of people's lives. Further, the societal and cultural expectations and roles specified to males and females greatly contribute to the way each gender deals with different situations in life (Lengua \&Stormshak, 2000). In addition, the differences in resilience and aggression due to gender are largely contingent on the variations in the mechanisms and resources that both males and females use to manage their functioning during the times of distress (Liddon, et al., 2018).

Literature concerning the influence of gender on resilience points toward diverse outcomes. According to some researches, females demonstrate lower level of resilience compared to the males going through the same aversive conditions (Rodriguez-Llanes, et al., 2013). Akin to this, a study conducted by Masood, Masud, and Mazahir (2016) in Lahore, Pakistan also indicated significantly high level of resilience in males compared to their female counterparts. Erdogana, Ozdoganb, \& Erdogan (2015) hypothesized that one reason for this could be that males are comparatively less emotionally sensitive and vulnerable than females. This assists males in keeping themselves controlled and act with resilience while encountering challenges. In contradiction to this, Yang, Wang, Zhang, Zeng, and Ma (2014) found that women are more resilient than men. The researchers 
rationalized that the tendency of women to be good at communication skills could be a reason that makes them better at emancipating their negative thoughts and emotions which subsequently helps them in positive cognitive reappraisal and thus, enhances their resilience.

Several researches indicate that the degree to which various protective and risk factors influence resilience tends to be considerably effected by gender. Factors such as social support and family bonding have been observed to enhance resilience in females more than their male counterparts. Literature indicates that females are more inclined towards looking for support from their social bonds, whereas, males rely more on using individualistic ways of dealing with challenging times (Sneed et al., 2006). Additionally, Werner (2005) noted that rules and regulations in a household specified for males and females such as the extent of autonomy provided to each gender, support for emotional expression, etc. also tends to mediate resilience differently for both the genders.

Considering gender difference in aggression, the long-standing perception is that aggression is higher in males than females. Nonetheless, literature indicates mixed findings in this context. Hay (2007) observed that males manifest more aggression compared to females. The researcher postulated that males typically prefer to engage in activities that stimulate aggressive tendencies whereas females choose prosocial activities that lead them towards passivity. On the other hand, some researches highlight that with the changing times, females are being observed to manifest higher level of aggression in comparison to males (Jagers, Sydnor, Mouttapa, \& Flay, 2007). Moreover, a study conducted in Karachi, Pakistan by Khan, Quadri, and Aziz (2014) indicated lack of gender difference in aggressive behaviors.

Factors such as self-esteem and concerns related to one's social standing have been identified as factors that affect aggressive tendencies among males and females. As noted by Campbell (1999), males have been observed to be show relatively higher concerns in regards to their status in the society which also affects their self-esteem. In order to maintain their social prestige and dominance to enhance their self-esteem, males tend to adopt overt means of aggression unlike females, who have lesser apprehension for social status and control. Further, literature indicates that relationships with family and peer groups, family size and family structure, internal factors such as conscientiousness, empathy, concern about other people's feelings, etc. also contribute in gender differences observed in aggression (Khan et al., 2014; Jagers et al., 2007). 


\section{Gender Difference in Resilience and Aggression among Adolescence, Early Adulthood and Middle Adulthood}

Studies conducted with the focus on the gender difference in resilience concerning three developmental stages (adolescence, early adulthood, and middle adulthood) point towards varied results. Ojha and Maurya (2013) found that during adolescence, while boys and girls do manifest different levels of adjustments with life circumstances, nonetheless, their level of resilience does not differ. In contradiction to this, findings of the study conducted on adolescents in Gujranwala, Pakistan by Sarwar, Inamullah, Khan, and Anwar (2010) indicate higher level of resilience among boys in comparison to girls. Considering gender difference in resilience among early adults, Shirley (2012) found higher resilience in males than females, whereas, in a study by McGloin and Widom (2001), females were found to be more resilient compared to males. In addition, literature for gender difference in resilience among middle-aged individuals point towards varied findings (Linda \& Caltabiano, 2009).

Literature based on studying aggression in adolescence, early adulthood, and middle adulthood from the perspective of potential gender differences indicates contradictory outcomes. Galambos, Barker, and Krahn (2006) explained that even though aggression is expressed by both the genders, however, among females, the manifestation of anger is higher during adolescence while it begins to decline later in life. On the other hand, Akhtar and Kushwaha (2015) found adolescent boys to express more aggression and anger compared to their counterparts. Contrary to this, in a meta-analytic study conducted by Card, Stucky, Sawalani, \& Little (2008) on gender differences in aggression among adolescents, boys and girls did not seem to differ in their level of aggression. Akin to this, taking into view the gender differences in aggression during early adulthood, literature signifies diverse results with some pointing towards higher aggression among young males whereas others indicating the opposite (Debowska, Mattison, \& Boduszek, 2015). Further, considering gender difference in aggression during middle adulthood, some researches indicate an absence of gender difference considering aggression and have found that women tend to manifest aggression on an equal level as men (Gierczyk, Fullard, \& Dobosz, 2017).

\section{Objectives}

It is evident from the literature review that research work focusing on the gender difference in resilience and aggression considering different developmental stages is fairly scarce specifically in Pakistan. In addition to this, inconsistent and varied research outcomes justify the need for examining this research domain further. Moreover, keeping 
in view that the ways in which people react and respond during stressful times vary from culture to culture, it is substantial to examine this realm of research from a Pakistani perspective. Therefore, as a step towards bridging the research gap, this study would not only focus on the differences in resilience and aggression between males and females but would also investigate the gender differences in these variables among adolescence, early adulthood, and middle adulthood. Studying these factors would subsequently contribute in developing gender-specific as well as age-specific interventions to enhance resilience and manage aggression among the people of Pakistan.

\section{Research Hypotheses}

In view of the study's objectives, it was hypothesized that:

1. There will be a difference in resilience between males and females

2. There will be gender differences in resilience in adolescence, early adulthood, and middle adulthood

3. There will be a difference in aggression between males and females

4. There will be gender differences in aggression in adolescence, early adulthood, and middle adulthood

\section{Method}

\section{Participants}

Total 600 participants (300 males; 300 females) were recruited through purposive sampling from various organizations, educational institutes, and communities of Karachi, Pakistan. All the participants were aged between 13 to 55 years $\left(M_{\text {age }}=28.24\right.$ years, $S D=$ 12.12). The sample was categorized into three age groups and each group comprised of 200 participants (100 males; 100 females); adolescence $\left(M_{\text {age }}=15.02\right.$ years; $\left.S D=1.39\right)$, early adulthood $\left(M_{\text {age }}=27.03\right.$ years; $\left.S D=4.19\right)$, and middle adulthood $\left(M_{\text {age }}=42.67\right.$ years; $S D=6.04$ ). Additionally, in line with the prerequisite of scales used, grade 7 was the minimum educational level for inclusion in the study.

\section{Instruments}

\section{Respondent Information Form}

This was self-developed to accumulate basic demographic data of the participants such as gender, age, level of education, and other pertinent information. 


\section{The Brief Resilience Scale}

The self-report instrument, Brief Resilience Scale (BRS; Smith et al., 2008), was used to measure resilience. The BRS has total six items and the responses are rated using a fivepoint Likert scale. All the even-numbered items are reversely scored followed by calculating a mean of total items.

\section{Short Form of the Buss-Perry Aggression Questionnaire}

Aggression was measured using Short Form of the Buss-Perry Aggression Questionnaire (BPAQ - SF; Bryant \& Smith, 2001). The BPAQ-SF is a self-rating questionnaire with 12 items allocated in four subscales (physical aggression; verbal aggression; anger; hostility - three items each). The responses are rated on a five-point Likert scale. Total aggression score is calculated through dividing the sum of all items by 12 , whereas, for separate subscale scores, the sum of each subscale is divided by three.

\section{Procedure}

A brief introduction to the study objectives was followed by taking the consent for voluntary participation from all the participants and guardians/caretakers (for adolescents). Further, assurance of the anonymity of information and the right to withdraw consent was also given to the participants after that they were requested to fill the study protocols. The participants were then given instructions on filling the research measures. Throughout the process, the researcher was available to provide the required assistance to the participants.

\section{Results}

Table - 1

Gender difference in resilience $(N=600)$

\begin{tabular}{|c|c|c|c|c|c|c|c|c|}
\hline Variable & \multicolumn{3}{|c|}{ Male } & \multicolumn{3}{c|}{ Female } & $\boldsymbol{t}$ & $\boldsymbol{p}$ \\
\hline & $\boldsymbol{N}$ & $\boldsymbol{M}$ & $\boldsymbol{S D}$ & $\boldsymbol{N}$ & $\boldsymbol{M}$ & $\boldsymbol{S D}$ & $(\boldsymbol{d f}=\mathbf{5 9 8})$ & \\
\hline Resilience & 300 & 3.28 & .77 & 300 & 3.02 & .82 & -3.97 & .00 \\
\hline
\end{tabular}

Table 1 demonstrates the analysis indicating a significant gender difference $(t(598)=$ $3.97, p<.01)$. Resilience was found to be higher in males $(M=3.28, S D=.77)$ compared to females $(M=3.02, S D=.82)$. 
Table -2

Gender difference in resilience among adolescence, early adulthood and middle adulthood $(N=600)$

\begin{tabular}{|c|c|c|c|c|c|c|c|c|c|}
\hline \multirow[t]{2}{*}{ Variable } & \multirow[t]{2}{*}{ Age Group } & \multicolumn{3}{|c|}{ Male $(n=300)$} & \multicolumn{3}{|c|}{ Female $(n=300)$} & \multirow{2}{*}{\begin{tabular}{c|}
$t$ \\
$(d f=198)$
\end{tabular}} & \multirow[t]{2}{*}{$p$} \\
\hline & & $N$ & $M$ & $S D$ & $N$ & $M$ & $S D$ & & \\
\hline \multirow{3}{*}{ Resilience } & Adolescence & 100 & 3.27 & .69 & 100 & 2.85 & .71 & -4.21 & .00 \\
\hline & Early Adulthood & 100 & 3.53 & .65 & 100 & 3.06 & .86 & -4.33 & .00 \\
\hline & $\begin{array}{c}\text { Middle } \\
\text { Adulthood }\end{array}$ & 100 & 3.03 & .88 & 100 & 3.14 & .86 & .89 & .37 \\
\hline
\end{tabular}

Table 2 shows that the analysis indicated significant gender difference in adolescence $(t$ $(198)=-4.21, p<.01)$ in which higher resilience was found in males $(M=3.27, S D=.69)$ compared to females $(M=2.85, S D=.71)$. Similarly, significant gender difference was found in early adulthood $(t(198)=-4.33, p<.01)$ in which males had higher resilience $(M$ $=3.53, S D=.65)$ than females $(M=3.06, S D=.86)$. Further, in middle adulthood, insignificant gender difference was found $(t(198)=.89, p>.05)$.

Table -3

Gender difference in aggression, physical aggression, verbal aggression, anger and hostility $(N=600)$

\begin{tabular}{|l|c|c|c|c|c|c|c|c|}
\hline \multicolumn{1}{|c|}{ Variable } & \multicolumn{3}{c|}{ Male } & \multicolumn{3}{c|}{ Female } & $\boldsymbol{t}$ & $\boldsymbol{p}$ \\
\hline & $\boldsymbol{N}$ & $\boldsymbol{M}$ & $\boldsymbol{S D}$ & $\boldsymbol{N}$ & $\boldsymbol{M}$ & $\boldsymbol{S D}$ & $(\boldsymbol{d f}=\mathbf{5 9 8})$ & \\
\hline Aggression & 300 & 2.82 & .67 & 300 & 2.87 & .65 & .85 & .39 \\
\hline Physical Aggression & 300 & 2.45 & .99 & 300 & 2.26 & .92 & -2.47 & .01 \\
\hline Verbal Aggression & 300 & 2.83 & .92 & 300 & 2.76 & .89 & -.94 & .34 \\
\hline Anger & 300 & 2.85 & .88 & 300 & 3.12 & .89 & 3.81 & .00 \\
\hline Hostility & 300 & 2.98 & .84 & 300 & 3.00 & .88 & .37 & .70 \\
\hline
\end{tabular}

Table 3 demonstrates that the analysis indicated overall non-significant gender difference in aggression $(t(598)=.85, p>.05)$. Further, among the four components of aggression, significant gender difference was observed in physical aggression $(t(598)=-2.47, p<.05)$ and anger $(t(598)=3.81, p<.01)$. Males appeared to have higher physical aggression $(M$ $=2.45, S D=.99)$ compared to females $(M=2.26, S D=.92)$, whereas, females showed higher anger $(M=3.12, S D=.89)$ than males $(M=2.85, S D=.88)$. On the other hand, insignificant gender difference was found in verbal aggression $(t(598)=-.94, p>.05)$ and hostility $(t(598)=.37, p>.05)$. 
Table -4

Gender Difference in Aggression among Adolescence, Early Adulthood, and Middle Adulthood $(N=600)$

\begin{tabular}{|c|c|c|c|c|c|c|c|c|c|}
\hline \multirow[t]{2}{*}{ Variable } & \multirow[t]{2}{*}{ Age Group } & \multicolumn{3}{|c|}{ Male $(n=300)$} & \multicolumn{3}{|c|}{ Female $(n=300)$} & \multirow{2}{*}{$\begin{array}{c}t \\
(d f=198)\end{array}$} & \multirow[t]{2}{*}{$p$} \\
\hline & & $N$ & $M$ & $S D$ & $N$ & $M$ & $S D$ & & \\
\hline \multirow{3}{*}{ Aggression } & Adolescence & 100 & 3.07 & .64 & 100 & 3.03 & .64 & -.44 & .66 \\
\hline & Early Adulthood & 100 & 2.65 & .67 & 100 & 2.79 & .67 & 1.47 & .14 \\
\hline & Middle Adulthood & 100 & 2.75 & .64 & 100 & 2.79 & .64 & .44 & .65 \\
\hline
\end{tabular}

Table 4 shows that the analysis indicated non-significant gender difference in aggression among adolescence $(t(198)=-.44, p>.05)$, early adulthood $(t(198)=1.47, p>.05)$, and middle adulthood $(t(198)=.44, p>.05)$.

\section{Discussion}

Results of the present study indicated high resilience among males than females. Corroborating this result, Malik \& Afzal (2015) postulated that higher level of autonomy and power given to males in Pakistan's patriarchal society could be a determinant in making them strong enough to deal with adversities and subsequently manifesting resilience more than females. In the similar vein, examining post-flood management and resilience in Sindh, Pakistan, Drolet and colleagues (2015) concluded that the Pakistani cultural practices of restricting and overloading females with responsibilities and rigid expectations increases their vulnerability to stressors and consequently makes them less resilient than males.

Data analysis further indicated significantly higher resilience in males than females in adolescence and early adulthood. Consistent with these results, Sharif and Akhtar (2018) found adolescent boys to be more resilient than girls. The researchers elucidated that Pakistani socio-cultural custom of giving high importance to boys substantially contributes in enhancing their resilience. Further, studying resilience in early adults, Zubair, Kamal, \& Artemeva (2018) noted that it might be the higher vulnerability of females towards negative emotions which adversely impacts their level of resilience. In addition, for the results lack of gender difference in middle adulthood might be the increased learning through experiences of middle-aged individuals. By the time people, irrespective of their gender, enter into the middle stage of life, they are equipped with several ways to deal with different situations and, consequently, are better able to adapt in a variety of circumstances which boosts their level of resilience. Similar notion was also highlighted by Werner (2005) who observed that the middle and old phase of life gives way to growth and learning which leads to numerous desirable changes including enhancement in resilience in an individual among both males and females. 
Additionally, the results indicated insignificant gender difference in overall aggression. Warburton and Anderson (2015) noted that males and females do not differ in aggression; rather, males use more direct forms of aggression whereas females are inclined towards indirect forms. Further, akin to the present study's results, Iftikhar \& Malik (2014) also found higher physical aggression in males than females. Considering Pakistani sociocultural factors, the reason for this might be the acceptance of active and open expression of aggression from males but not from females. Moreover, supporting our study's results, previous research work also indicates higher level of anger among females in comparison to males (Evren et al., 2015). The resulted lower level of anger in males could be attributed to the Pakistani society's expectation of males to be less emotionally expressive in comparison to females.

Lastly, insignificant gender differences were found among adolescence, early adulthood, and middle adulthood. Substantiating these results, Khan (2006) highlighted that aggression appears to be equally present in both males and females from childhood to adulthood, however, the differences, if any, are attributed to the societal customs restricted for each gender. Additionally, the resulted lack of gender difference in aggression could also be attributed to the fact that due to the long-conceived perception of males more aggressive, an ample amount of research work has ignored to study aggression in females as thoroughly as they have studied aggression in males, hence, it is still an area that needs to be further explored in depth.

\section{Conclusions}

Keeping objectives of the present study in view, differences in resilience and aggression between males and females were investigated. Moreover, gender differences in resilience and aggression were also examined among three developmental stages: adolescence, early adulthood, and middle adulthood. The analysis indicated high resilience in males compared to females, whereas, non-significant gender difference was found in aggression. In addition, males in adolescence and early adulthood were found to be more resilient; on the other hand, insignificant gender difference was seen in middle adulthood. The results further indicated non-significant gender difference in overall aggression while physical aggression was higher in males and anger was found to be higher in females. Lastly, aggression in both males and females was observed to have an insignificant difference in adolescence, early and middle adulthood.

\section{Recommendations}

The present study highlights that there is a considerable need to develop strategies and interventions to promote resilience. The upcoming researches should also focus on the potential reasons for lower resilience in females so that gender-specific programs to build 
and enhance resilience can be developed. Moreover, it should be kept in mind that aggression can have harmful effects on both physical and psychological health of the individual as well as of those in the surroundings. Therefore, in order to transition smoothly from one stage of life to another while encountering all the challenges it brings, both males and females equally need to learn anger management skills.

\section{References}

Ahsan, M. (2015). Physical, Verbal, Anger and Hostility Aggressiveness in University's Physical Education Students. International Journal of Sports and Physical Education, vol.1:2, pp.20-23. Retrieved July 11, 2019 from https://www.arcjournals.org/pdfs/ ijspe/v1-i2/4.pdf

Akbari, B. (2017). Effectiveness of Training Psychological Resilience on Aggression and Happiness among Students. Journal of Holistic Nursing and Midwifery, vol.27:1, pp.1-7

Akhtar, J. \& Kushwaha, A. (2015). Gender Difference in Aggressive Behavior of Adolescents. Indian Journal of Applied Research, vol.5:1, pp.525-527.

Archer, J. \& Coyne, S. (2005). An Integrated Review of Indirect, Relational and Social Aggression. Personality and Social Psychology Review, vol.9:3, pp.212-230.

Berkowitz, L. (1993). Aggression: Its Causes, Consequences and Control. McGraw-Hill, New York. p.485.

Bezek, E. (2010). Gender Differences in Resilience in the Emerging Adulthood Population (Master's Thesis). Rochester Institute of Technology. Retrieved April 28, 2019 fromhttps://scholarworks.rit.edu/cgi/viewcontent.cgi?article=10482\&context $=$ theses

Blatt-Eisengart, I., Drabick, D., Monahan, K. \& Steinberg, L. (2009). Sex Differences in the Longitudinal Relations among Family Risk Factors and Childhood Externalizing Symptoms. Developmental Psychology, vol.45:2, pp.491-502.

Bryant, F. \& Smith, B. (2001). Refining the Architecture of Aggression: A Measurement Model for the Buss-Perry Aggression Questionnaire. Journal of Research in Personality, vol.35, pp.138-167. 
Bushman, B. \& Huesmann, L. (2010). Aggression. In S. T. Fiske, D. T. Gilbert, \& G. Lindzey (Eds.), Handbook of Social Psychology, pp. 833-863. Hoboken, NJ, US: John Wiley \& Sons Inc.

Campbell, A. (1999). Staying Alive: Evolution, Culture and Women's Intrasexual Aggression. Behavioral and Brain Sciences, vol.22:2, pp.203-252.

Card, N., Stucky, B., Sawalani, G. \& Little, T. (2008). Direct and Indirect Aggression duringChildhood and Adolescence: A Meta-Analytic Review of Gender Differences, Intercorrelations and Relations to Maladjustment. Child Development, vol.79:5, pp.1185-1229.

Carmona-Halty, M., Salanova, M., Llorens, S. \& Schaufeli, W. (2019). How Psychological Capital Mediates between Study-Related Positive Emotions and Academic Performance. Journal of Happiness Studies, vol.20:2, pp.605-617.

Chaplin, T. (2015). Gender and Emotion Expression: A Developmental Contextual Perspective. Emotion Review: Journal of the International Society for Research on Emotion, vol.7:1, pp.14-21.

Debowska, A., Mattison, M. \& Boduszek, D. (2015). Gender Differences in the Correlates of Reactive Aggression. Polish Psychological Bulletin, vol.46:3, pp.469-476.

Drolet, J., Dominelli, L., Alston, M., Ersing, R., Mathbor, G. \& Wu, H. (2015). Women Rebuilding Lives Post-Disaster: Innovative Community Practices for Building Resilience and Promoting Sustainable Development. Gender \& Development, vol.23:3, pp.433-448.

Erdogana, E., Ozdoganb, O. \& Erdogan, M. (2015). University Students' Resilience Level: The Effect of Gender and Faculty. Procedia - Social and Behavioral Sciences, vol.186,pp.1262-1267.

Evren, C., Bozkurt, M., Çiftçi-Demirci, A., Evren, B., Can, Y. \& Umut, G. (2015). Differences between Genders According to Psychological and Behavioral Variables among 10th Grade Students in Istanbul. Anatolian Journal of Psychiatry, vol.16:2, pp.77-84.

Galambos, N., Barker, E. \& Krahn, H. (2006). Depression, Self-Esteem and Anger in Emerging Adulthood: Seven-Year Trajectories. Developmental Psychology, vol.42:2, pp.350-365. 
Gierczyk, M., Fullard, M. \& Dobosz, D. (2017). Aggression from a Gender Perspective and the Development of a Moral Compass. Journal of Gender and Power, vol.8:2, pp.9-26. Retrieved from http://gender-power.amu.edu.pl/JGP_Vol_8_No_2_B.pdf

Hay, D. (2007). The Gradual Emergence of Sex Differences in Aggression: Alternative Hypotheses. Psychological Medicine, vol.37:11, pp.1527-1537.

Iftikhar, R. \& Malik, F. (2014). Translation and Validation of Aggression Questionnaire in a Pakistani Children Cohort. Pakistan Journal of Social and Clinical Psychology, vol.12:1, pp.39-45.

Jaffee, S., Caspi, A., Moffitt, T., Polo-Tomás, M. \& Taylor, A. (2007). Individual, Family, and Neighborhood Factors Distinguish Resilient from Non-Resilient Maltreated Children: A Cumulative Stressors Model. Child Abuse \& Neglect, vol.31:3, pp.231-253.

Jagers, R., Sydnor, K., Mouttapa, M. \& Flay, B. (2007). Protective Factors Associated with Preadolescent Violence: Preliminary Work on a Cultural Model. American Journal of Community Psychology, vol.40:1-2, pp.138-145.

Khan, F. N. (2006). Age Differences in Expression of Aggression in Men and Women. Journal of Independent Studies and Research, vol.4:1, pp.29-32.

Khan, M., Quadri, S. \& Aziz, S. (2014). Association of Family Structure and its Environment with Aggressive Behaviour of Children (6-8years) in a Rural Community. Journal of Child and Adolescent Behavior, vol.2,p.125.

Kim, J., Seok, J., Choi, K., Jon, D. I., Hong, H., Hong, N. \& Lee, E. (2015). The Protective Role of Resilience in Attenuating Emotional Distress and Aggression Associated with Early-Life Stress in Young Enlisted Military Service Candidates.Journal of Korean Medical Science, vol.30:11, pp.1667-1674.

Kokko, K. \& Pulkkinen, L. (2000). Aggression in Childhood and Long-Term Unemployment in Adulthood: A Cycle of Maladaptation and Some Protective Factors. Developmental Psychology, vol.36:4, pp.463-472.

Lengua, L. \& Stormshak, E. (2000). Gender, Gender Roles and Personality: Gender Differences in the Prediction of Coping and Psychological Symptoms. Sex Roles: A Journal of Research, vol.43:11-12, pp.787-820. 
Liddon, L., Kingerlee, R. \& Barry, J. (2018). Gender Differences in Preferences for Psychological Treatment, Coping Strategies and Triggers to Help-Seeking. The British Journal of Clinical Psychology, vol.57:1, pp.42-58.

Masood, A., Masud, Y. \& Mazahir, S. (2016). Gender Differences in Resilience and Psychological Distress of Patients with Burns. Burns: Journal of the International Society for Burn Injuries, vol.42:2, pp.300-306.

Masten, A. S. (2011). Resilience in Children Threatened by Extreme Adversity: Frameworks for Research, Practice and Translational Synergy. Development and Psychopathology, vol.23:2, pp.493-506.

Malik, S. \& Afzal, N. (2015). Predictors of Quality of Life and Resilience among Outpatients with Heart Diseases. Journal of Pakistan Psychiatric Society, vol.12:3, pp.31-33.

McGloin, J. \& Widom, C. (2001). Resilience among Abused and Neglected Children Grown Up. Development and Psychopathology, vol.13:4, pp.1021-1038.

Mwangi, C. \& Ireri., A. (2017). Gender Differences in Academic Resilience and Academic Achievement among Secondary School Students in Kiambu County, Kenya. Psychology and Behavioral Science: International Journal, vol.5:5, pp. 001-007.

Nisa, A. \& Parveen, S. (2019). Perception of Female Teachers in Transferring Peace Concepts among Adult Students. Pakistan Journal of Gender Studies, vol.18, pp.1-22.

Ojha, S. \& Maurya, P. (2013). Resilience and Adjustment of Adolescents: A Gender Perspective. Indian Journal of Positive Psychology, vol.4:1, pp.39-42.

Parsons, S., Kruijt, A. \& Fox, E. (2016). A Cognitive Model of Psychological Resilience. Journal of Experimental Psychopathology, vol.7:3, pp.296-310.

Rodriguez-Llanes, J., Vos, F. \& Guha-Sapir, D. (2013). Measuring Psychological Resilience to Disasters: Are Evidence Based Indicators an Achievable Goal? Environmental Health, vol.12, pp.115-125.

Rubio-Garay, F., Carrasco, M. \& Amor, P. (2016). Aggression, Anger and Hostility: Evaluation of Moral Disengagement as a Mediational Process. Scandinavian Journal of Psychology, vol.57:2, pp.129-135. 
Rutter, M. (2006). Implications of Resilience Concepts for Scientific Understanding. Annuals of the New York Academy of Sciences, vol.1094, pp.1-12.

Sarwar, M., Inamullah, H., Khan, N. \& Anwar, N. (2010). Resilience and Academic Achievement of Male and Female Secondary Level Students in Pakistan. Journal of College Teaching \& Learning, vol.7:8, pp.19-24.

Sharif, S. \& Akhtar, T. (2018). Relationship of Late Adolescent's Attachment Styles with Suicidal Ideation and Resilience. Foundation University Journal of Psychology, vol.2:2, pp.96-120. Retrieved fromhttp://fujp.fui.edu.pk/revolume4/Fujp\%204.pdf

Shirley, L. (2012). Resilience to Childhood Abuse and Neglect in College Students (Doctoral Dissertation, Colorado State University, Fort Collins, Colorado). Retrieved August 8, 2019 from https://mountainscholar.org/bitstream/handle/ 10217/67948/Shirley_colostate_0053A_11214.pdf?sequence=1\&isAllowed=y

Smith, B., Dalen, J., Wiggins, K., Tooley, E., Christopher, P. \& Bernard, J. (2008). The Brief Resilience Scale: Assessing the Ability to Bounce Back. International Journal of Behavioral Medicine, vol.15:3, pp.194-200.

Sneed, J., Johnson, J., Cohen, P., Gilligan, C., Chen, H., Crawford, T. \& Kasen, S. (2006). Gender Differences in the Age-Changing Relationship between Instrumentality and Family Contact in Emerging Adulthood. Developmental Psychology, vol.42:5, pp.787-797.

Warburton, W. \& Anderson, C. (2015). Aggression, Social Psychology of. In J. D. Wright (Ed.), International Encyclopedia of the Social \&Behavioral Sciences (2nd ed., pp. 373-380). Amsterdam: Elsevier.

Werner, E. (2005). Resilience and Recovery: Findings from the Kauai Longitudinal Study. Focal Point: Research, Policy and Practice in Children's Mental Health, vol.19:1, pp.11-14. Retrieved August 26, 2019 from https:/www.pathwaysrtc.pdx.edu/pdf/ fpS0504.pdf

World Economic Forum (2018). The Global Gender Gap Report 2018. Retrieved from http://www3.weforum.org/docs/WEF_GGGR_2018.pdf

Yang, Z., Wang, J., Zhang, B., Zeng, Y. \& Ma., H. (2014). Factors Influencing Resilience in Patients with Burns during Rehabilitation Period. International Journal of Nursing Sciences, vol.1:1, pp.97-101. 
Zubair, A., Kamal, A. \& Artemeva, V. (2018). Mindfulness and Resilience as Predictors of Subjective Well-Being among University Students: A Cross-Cultural Perspective. Journal of Behavioral Sciences, vol.28:2, pp.1-19.

Ms. Sabahat Naseem is Ph.D Scholar in the Institute of Clinical Psychology, University of Karachi.

Dr. Seema Munaf is Meritorious Professor in the Institute of Clinical Psychology, University of Karachi. 